

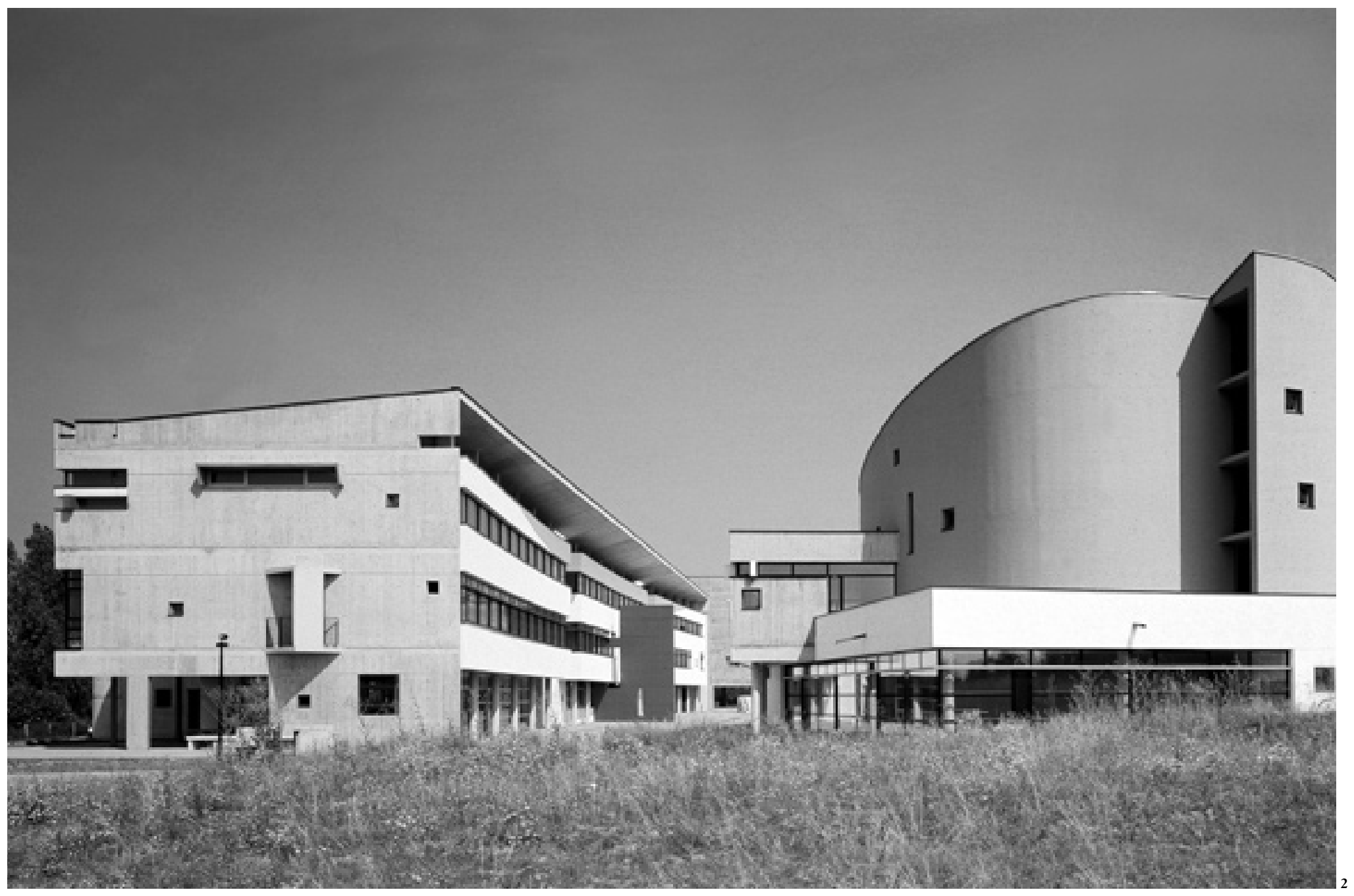

\section{de Franche Comté}

carácter propio y autonomía de funcionamiento. De esta forma se definieron cuatro primeras unidades: biblioteca, anfiteatro, la Facultad de Ciencias Humanas y el Instituto Universitario de Tecnología.

Estas cuatro primeras unidades se organizaron de manera de crear un centro, un espacio bien definido capaz de unificar y caracterizar desde la primera etapa al proyecto -pues existía el riesgo que el proyecto no se desarrollara más allá de la primera etapa-. Este centro se plantea como una plaza de $64 \times 32 \mathrm{~m}$ (estas dimensiones y geometría permitirían el desarrollo ulterior del proyecto) completamente abierta hacia la ciudad. La plaza se transforma en una verdadera plaza urbana; la escala monumental de la biblioteca proporcionaría el sentido institucional del proyecto.

La biblioteca universitaria y el anfiteatro se piensan como lugares abiertos a las actividades urbanas. Actualmente en ellos ocurren celebraciones que no están directamente relacionadas con la universidad: la ciudad entera ocupa estos espacios y al mismo tiempo la vida urbana en la plaza transforma el lugar.

La plaza será también el centro del desarrollo futuro. En el sentido oriente - poniente dos ejes ordenan el crecimiento y determinan los lugares donde serán construidas las nuevas unidades.

En el sentido norte - sur otra plaza, abierta a la circulación vehicular, viene a fortalecer la relación entre la ciudad y la zona universitaria. Ubicada entre la biblioteca y la residencia de los estudiantes, concentra las actividades deportivas, cafetería, restaurante y diferentes actividades relacionadas a la vida de los estudiantes.

En la zona sur se ha previsto la construcción de un jardín que tendría como tema la escultura, estableciendo un equilibrio entre las zonas públicas minerales y las vegetales.

Actualmente hay un conjunto de nuevos edificios en construcción o en etapa de estudio, siempre con la idea de conservar una fuerte unidad arquitectónica. ARQ
1 El conjunto desde el oriente. Bloque de aulas

2 Campus Montbéliard.

La primera etapa del proyecto

vista desde el sur: bloque de

aulas poniente y anfiteatro 

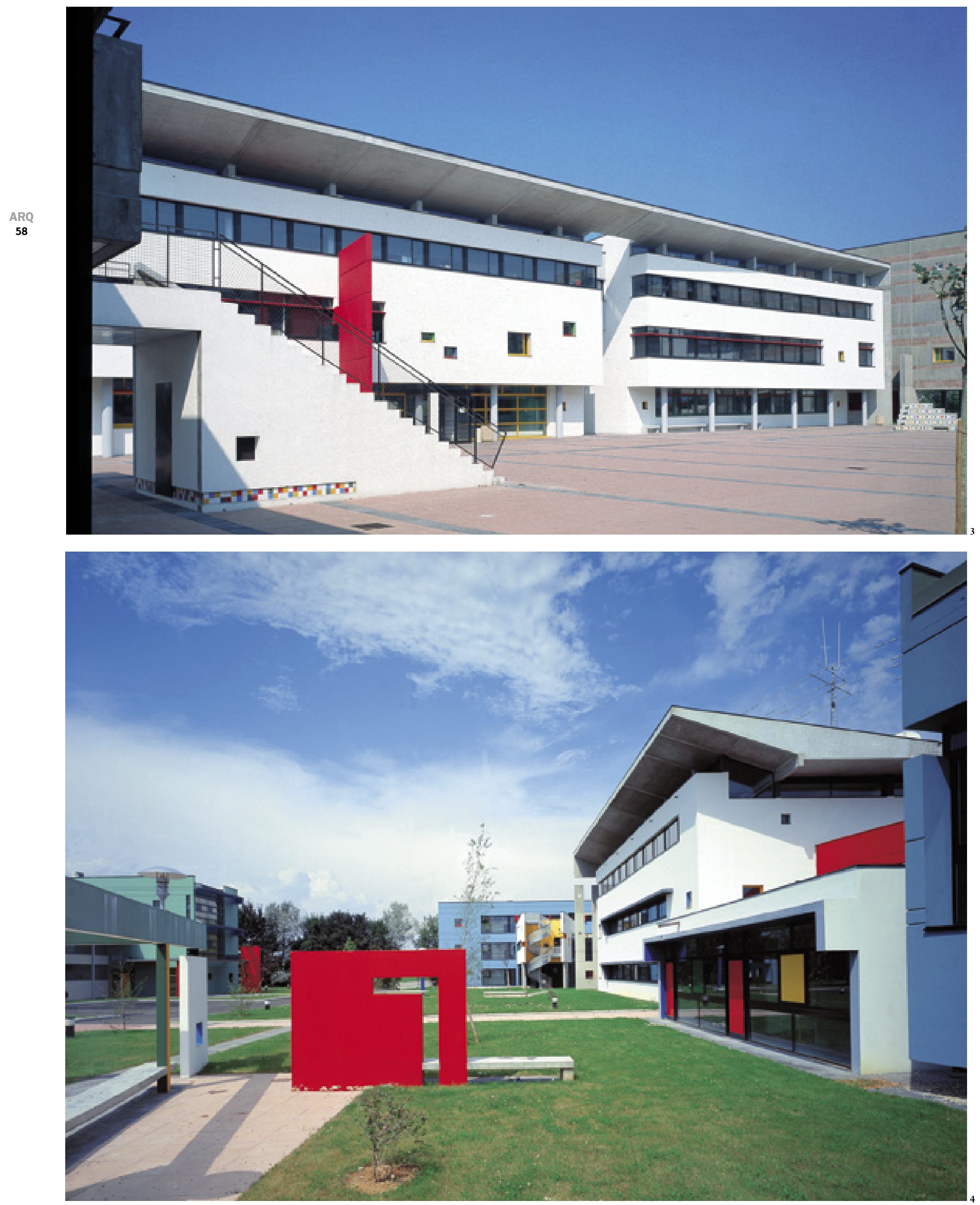


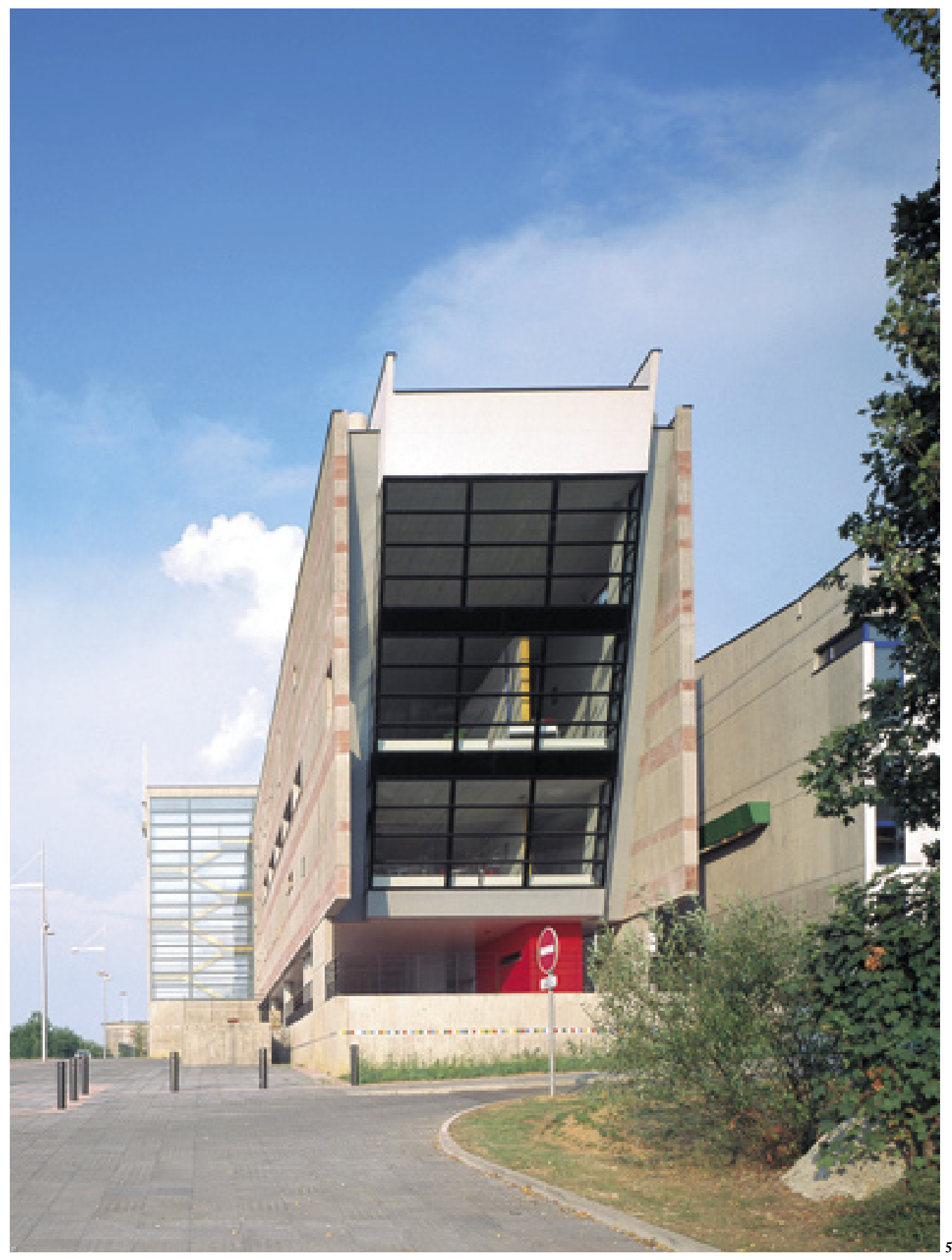

3 Ala poniente, bloque de aulas primera etapa

4 Campus Montbéliard, segunda

etapa. Instituto Universitario

de Tecnología. Vista del jardín

entral hacia el norte

5 Fachada poniente, biblioteca

6 Escalera, Instituto

Universitario de Tecnología,

bloque norte

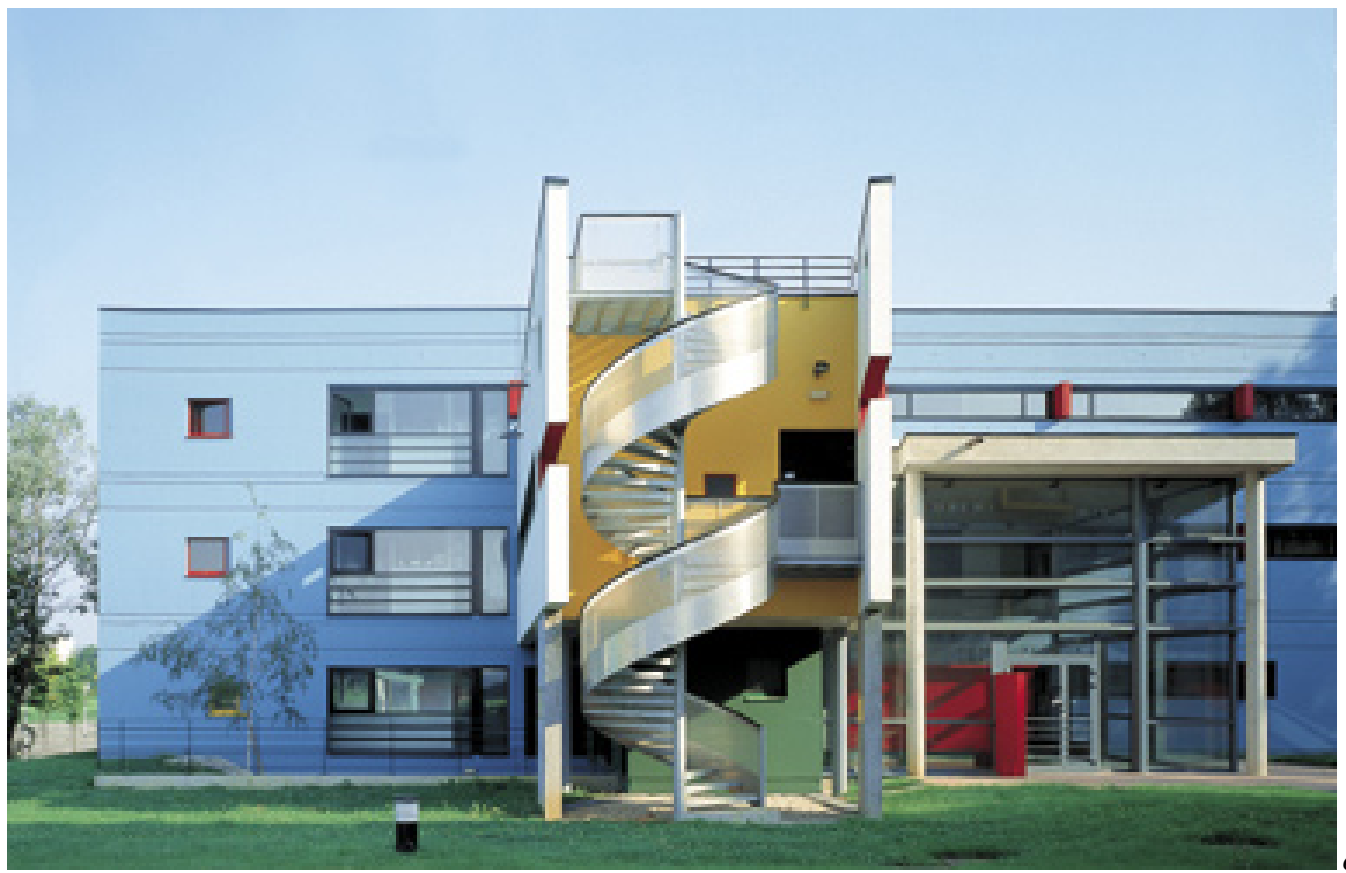



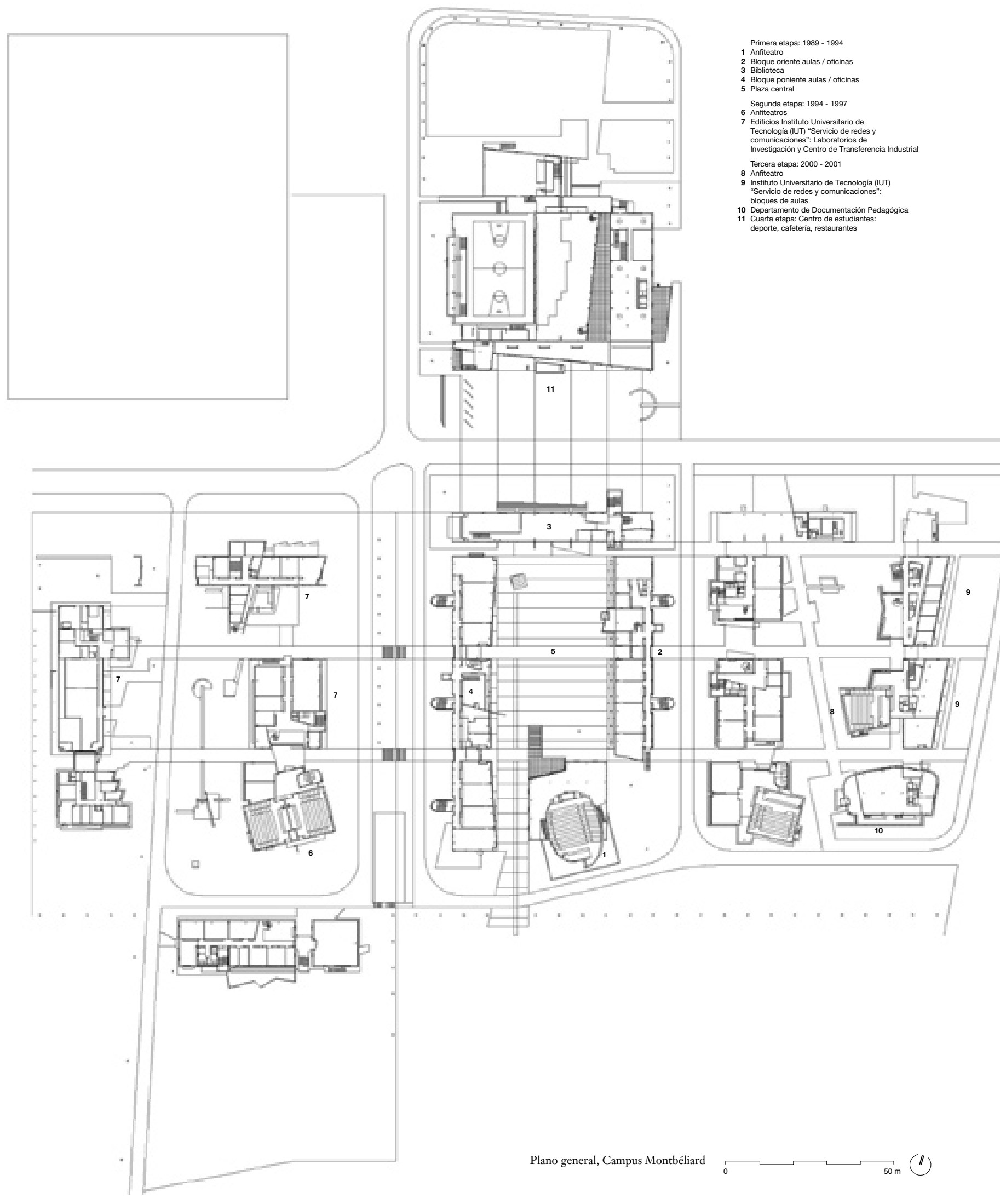

Th:

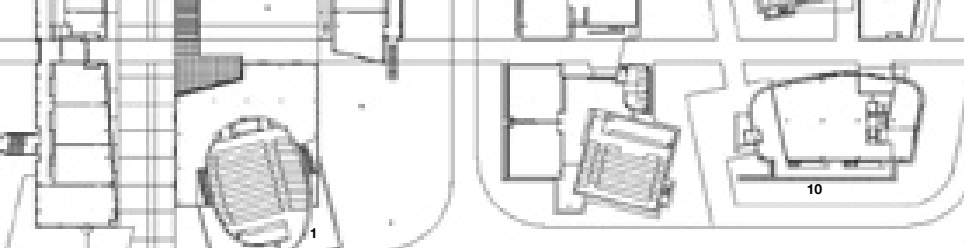

Plano general, Campus Montbéliard

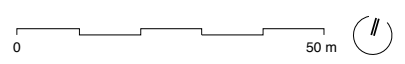


7 Circulación interior, Instituto Universitario de Tecnología

8 Vista de la plaza central hacia

el norte. Al fondo la biblioteca

9 La biblioteca. A la derecha,

un bloque de aulas
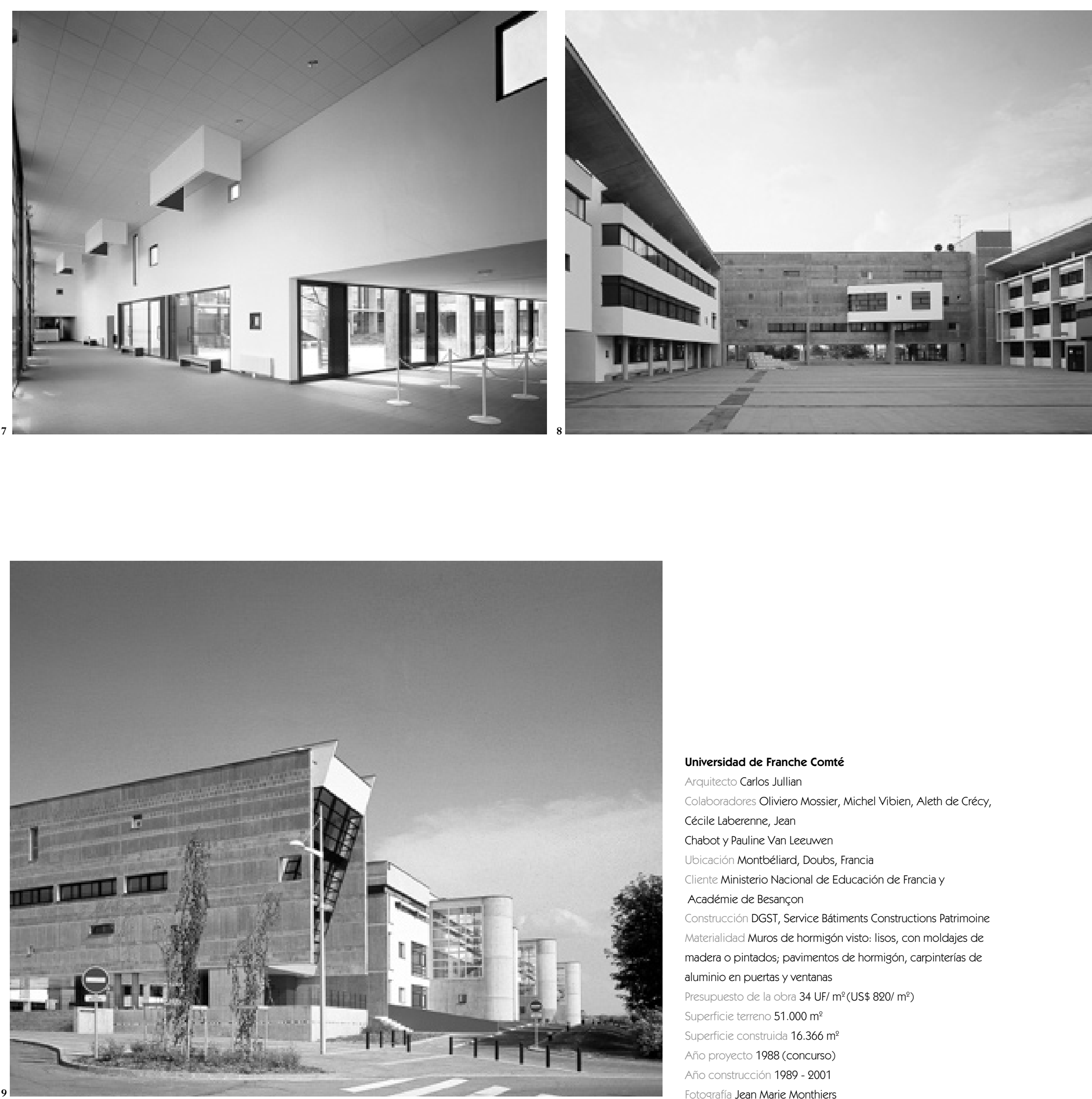

Universidad de Franche Comté

Arquitecto Carlos Jullian

Colaboradores Oliviero Mossier, Michel Vibien, Aleth de Crécy, Cécile Laberenne, Jean

Chabot y Pauline Van Leeuwen

Ubicación Montbéliard, Doubs, Francia

Cliente Ministerio Nacional de Educación de Francia y

Académie de Besançon

Construcción DGST, Service Bátiments Constructions Patrimoine Materialidad Muros de hormigón visto: lisos, con moldajes de madera o pintados; pavimentos de hormigón, carpinterías de aluminio en puertas y ventanas

Presupuesto de la obra 34 UF/ m² (US\$ 820/ $\mathrm{m}^{2}$ )

Superficie terreno $51.000 \mathrm{~m}^{2}$

Superficie construida $16.366 \mathrm{~m}^{2}$

Año proyecto 1988 (concurso)

Año construcción 1989 - 2001

Fotografía Jean Marie Monthiers 